\title{
A entrevista como tema de pesquisa no campo da comunicação
}

\section{Interview as a research theme in the field of communication}

Agnes Francine de Carvalho Mariano

Universidade Federal de Ouro Preto (UFOP)

<agnesmariano@gmail.com>

\author{
Como citar este artigo (How to cite this article): \\ MARIANO, Agnes Francine de Carvalho. A entrevista como tema de pesquisa no campo da comunicação. \\ Revista Famecos, Porto Alegre, v. 25, n. 2, p. 1-17, maio, junho, julho e agosto de 2018: ID28307. \\ DOI: http://dx.doi.org/10.15448/1980-3729.2018.2.28307.
}

\section{RESUMO}

O objetivo do trabalho é investigar o que tem sido e o que não tem sido debatido a respei-to da entrevista na pesquisa científica brasileira no campo da comunicação. Inicialmente observamos pesquisas apresentadas nos últimos 10 anos no maior congresso da área. Foram identificados três eixos principais: discurso, interação e memória. Em seguida, re-visitamos os dois trabalhos mais citados pelos pesquisadores, de Edgar Morin e Cremilda Medina. Identificamos aspectos de destaque na formulação de ambos e também os silen-ciados. A comparação desses aspectos com a abordagem da entrevista em outro campo, o da história oral, demonstrou que, na comunicação, é preciso ampliar o debate, ainda incipiente, sobre temas como: relação de poder entre entrevistador e entrevistado; com-partilhamento de benefícios; elaboração de perguntas e entrevistas sobre traumas. A am-pliação desse debate justifica-se ainda pela dissonância entre práticas jornalísticas arrai-gadas e novas demandas da comunicação contemporânea.

Palavras-chave: Entrevista. Memória. História oral.

\section{ABSTRACT}

This article aims to investigate what has been and what has not been debated about interview in the scientific research in the field of communication on Brazil. Initially, were considered papers presented at the largest congress in this field, over the last 10 years. Three main axes were identified: discourse, interaction and memory. Consecutively, we revisited two researches most cited, written by Edgar Morin and Cremilda Medina. We identified important aspects about interview in both and points that were silenced. The comparison with the interview approach in another field, oral history, showed that is necessary to broaden the debate, still in early stages, about issues as: power relations between interviewer and interviewee; benefit sharing; formulating questions and interviews about traumas. The broadening of the debate is justified by the dissonance between established journalistic practices and the new demands of the contemporary communication.

Keywords: Interview. Memory. Oral history.

O jornalismo passa por profundas transformações. Ou deveria estar passando, pois o modo como nos comunicamos mudou radicalmente nos últimos anos. Surgiram diversas espécies de "mídias complementares" (Sodré; Paiva, 2011) pautadas por outras lógicas e formas de conduta: blogueiros, 
celebridades das redes sociais, youtubers, tuiteiros, portais de notícias falsas. Desenvolvem-se ainda formas de compartilhamento de informações pautadas por novos princípios, como a ética hacker (Karam; Christofoletti, 2011). Analisando os dois pilares principais - apuração e redação - que embasaram por décadas o ensino e os estudos sobre o jornalismo, Sodré e Paiva afirmam que, nos últimos anos, a redação pouco mudou: "o velho e bom lead continua em ação e talvez muito mais vigoroso e resplandecente do que antes" (Sodré; Paiva, 2011 , p. 28). Para eles, a apuração no mundo digital, entretanto, seria "bastante diferente" do passado, com "baixa qualidade e excesso de fontes" (Sodré; Paiva, 2011 , p. 28). Mas em que medida as inevitáveis mudanças na apuração poderiam estar sintonizadas com novas demandas? Em que novos termos poderiam ser estabelecidas as relações entre jornalistas, leitores e fontes?

Em diálogo com todas essas questões buscaremos aqui rever um aspecto central da apuração no jornalismo: a entrevista. O presente artigo é parte inicial de uma investigação mais ampla que busca caracterizar como a entrevista vem sendo estudada na pesquisa científica brasileira recente no campo da comunicação. A expressão "entrevista" está sendo usada para definir a interação oral face a face, baseada no par dialógico pergunta-resposta, utilizada por jornalistas e outros profissionais da comunicação na elaboração de notícias, reportagens e documentários. A investigação partiu da produção dos últimos 10 anos veiculada em anais do maior congresso da área. Como um dos aspectos observados são os aportes teórico-disciplinares, chamou atenção a frequência com que dois autores são citados: o texto "A entrevista nas Ciências Sociais, no Rádio e Televisão", de Edgar Morin e o livro "Entrevista: o diálogo possível", de Cremilda Medina.

O objetivo é caracterizar, de forma introdutória, os principais aportes das pesquisas e discutir aspectos dos textos de Morin e Medina frequentemente explorados. Um exame cuidadoso nos ajuda a problematizar o que esses textos discutem e também o que não discutem. O objetivo é identificar os contornos das investigações sobre o tema - conceitos, aportes, perspectivas -, em que direção aponta e diálogos interdisciplinares. E também localizar debates ainda silenciados ou abordados com brevidade a respeito da entrevista. O que, em certa medida, aponta para o alcance e limites das nossas próprias pesquisas.

A propostaganha relevo quando seobserva que, a despeito da importância da entrevista para o jornalismo e a comunicação, a bibliografia sobre o tema é modesta. A entrevista vem sendo estudada de forma esporádica e fragmentada. São poucos os livros e artigos que tratam do tema e boa parte da bibliografia mais citada é antiga: os trabalhos de Morin e Medina foram publicados há 
mais de 20 anos. Quais os motivos desse desinteresse? A entrevista é um tema esgotado? Tudo já foi dito sobre ela? Entrevista não se estuda, entrevista se faz?

Desnaturalizar a entrevista e encará-la com a complexidade que lhe é inerente pode ter vários efeitos positivos. Pode repercutir no ensino, gerando um incremento de qualidade desse debate, ao invés da atual abordagem superficial das dimensões psico-afetivas e éticas relacionadas às entrevistas. Ao invés de um ensino que, em muitos momentos, limita-se à descrição de como "as coisas costumam ser feitas", acrescentar reflexões sobre "como as coisas poderiam ser feitas". O que pode vir, no futuro, a afetar positivamente as práticas profissionais relacionadas à entrevista. Além disso, o trabalho dos pesquisadores da comunicação que incluem as entrevistas em seus procedimentos metodológicos também pode vir a ampliar seus fundamentos. Assim, ao invés de depender de conceitos e premissas de outros campos, poderemos encontrar em pesquisas da comunicação bases para as nossas entrevistas científicas.

\section{Pesquisas sobre entrevista}

Para iniciar a caracterização da pesquisa sobre o tema da entrevista na comunicação, escolhemos observar um conjunto de anais do Congresso Brasileiro de Ciências da Comunicação. O evento, organizado há 40 anos pela Intercom - sociedade brasileira de estudos interdisciplinares da comunicação, "acontece desde 1977 e reúne, tradicionalmente, cerca de 3,5 mil pessoas, entre alunos de graduação e pós-graduação, pesquisadores e profissionais da área" (Intercom) e é o maior na área. Ainda que abrigue discussões pertinentes à comunicação, o que inclui relações públicas, publicidade, games, produção editorial, cinema, entre outras, o jornalismo tem presença forte em boa parte dos Grupos de Pesquisa (GP). A seleção do material que será aqui descrito foi feito por meio de consulta aos anais eletrônicos dos congressos nacionais que ocorreram entre 2005 e 2015 . É importante enfatizar que não se trata de uma pesquisa exaustiva, mas de uma abordagem inicial ${ }^{2}$.

Pesquisando a ocorrência da palavra entrevista na opção"Busca" dos anais chegamos a 23 artigos em que há, mesmo de forma breve, alguma discussão sobre o tema da entrevista. Os artigos foram apresentados nos seguintes GPs e NPs ${ }^{3}$ : Cinema; Comunicação, Mídias e Liberdade de Expressão; Comunicação

1 Os anais de 2016 não foram incluídos porque a busca por palavras-chave/título ainda estava indisponível quando os dados foram coletados.

2 Ainda que a Intercom disponibilize a versão digital dos anais, os sistemas de busca implementados têm limitações e não funcionam perfeitamente. Não é possível, por exemplo, incluir o resumo entre as opções de busca. Em nosso caso, seria preciso que o pesquisador tivesse usado a palavra "entrevista" no título ou como palavra-chave para que o artigo fosse localizado pela busca.

3 Núcleo de Pesquisa é a nomenclatura antiga. 
Visual; Gêneros Jornalísticos; Jornalismo Impresso; Jornalismo; Rádio e Mídia Sonora; Telejornalismo; Temas livres; Teorias da Comunicação; Televisão e Vídeo. Ao longo dos anos alguns desses grupos mudaram de nome ou deixaram de existir. Os três GPs com maior ocorrência de artigos foram os relacionados a jornalismo, rádio e telejornalismo. Ainda assim, em boa parte dos casos, a entrevista é discutida apenas em algum trecho.

E o que esses textos discutem a respeito da entrevista? Buscando uma síntese, é possível afirmar que as discussões tangenciam principalmente três eixos: discurso, interação e memória. Aparentemente, essa é uma sequência também cronológica. Ou seja, a abordagem discursiva aparece nos textos mais antigos, o interesse pela perspectiva da interação vem na sequência, enquanto o interesse pela memória predomina nos textos mais recentes, de 2012 a 2015. A seguir, uma descrição sintética de alguns debates a respeito desses três eixos.

Alguns artigos observaram as entrevistas numa perspectiva prioritariamente discursiva. Partindo da Teoria da Relevância, perguntas e respostas são transcritas e analisadas, buscando-se identificar momentos de imposição, desvios, contradições, condenação (Klockner, 2006). Tomando como base a análise do discurso, outra abordagem buscou descrever os gêneros de entrevistas e características discursivas dos papeis de entrevistador e entrevistado (Prata, 2005). Ou então, a partir da análise da conversação, foram identificadas as estratégias discursivas, especialmente as trocas de turnos e os tipos de atos de fala (Pessoa, 2005).

As pesquisas que observam a entrevista na perspectiva da interação discutem temas ligados à relação entre entrevistadores e entrevistados. Alguns exemplos: a necessidade de abertura ao diálogo (D'Almeida, 2006), de confiança entre as partes (Dias, 2007), a construção da escuta (D'Almeida, 2006), de uma escuta ativa (Martinez, 2007), a parceria entre entrevistadores e entrevistados (Gonçalves, 2012). Discute-se também como a emoção, a irritação, o constrangimento e a ironia (Puhl; Persch, 2012) participam dessa interação. Aparecem então temas como tensionamento, pressão (Braga, 2006), conflito (Giacomini, 2012), interação não-verbal (Martinez, 2007) e o papel desempenhado pelo público (Musse, 2013). Em alguns casos, os pesquisadores transcrevem e analisam perguntas e respostas de entrevistas (Ruela, 2011) ou descrevem a interação (Dias, 2007). Em outros momentos, quando a pesquisa envolveu a realização de entrevistas, são descritas as escolhas feitas durante o momento de interação entre entrevistador e entrevistado (Lamas e outros, 2011).

O conceito de memória, que vem ganhando relevância na área de comunicação nos últimos anos, também aparece nas abordagens sobre a 
entrevista ${ }^{4}$. Alguns autores defendem que a memória é o conteúdo com que se lida nas entrevistas (Giacomini, 2012) e discutem o papel do registro da fala na construção de um lugar de memória (Melo, 2015). Há o reconhecimento de que vivemos um fortalecimento dos discursos da memória, dos depoimentos, da "rememoração da experiência", no contexto de uma "guinada subjetiva" (Musse, 2013). Dialogando em alguns casos com a história oral, a relação com a entrevista é forte porque a oralidade é um dos principais abrigos da construção da memória. Memória que, ao permanentemente reelaborar o passado, é entendida como um campo de negociações (Musse; Arantes, 2012). E como ingrediente indispensável na construção das nossas identidades, o que inclui a memória individual e a coletiva:

[...] os acontecimentos vividos pessoalmente; os acontecimentos vividos por 'tabela' - acontecimentos vividos pelo grupo ou pela coletividade à qual a pessoa se sente pertencer; e os acontecimentos que não se situam dentro do espaço-tempo de uma pessoa ou grupo (Sousa, 2015, p. 8).

Talvez como consequência da aproximação do debate sobre a memória, alguns pesquisadores começam a esboçar dilemas éticos relacionados ao ato de entrevistar. Consequência porque, em áreas com maior tradição em investigações sobre a memória, especialmente a história oral, muitos desses dilemas são discutidos amplamente. Um artigo dedica certo tempo a tratar de possíveis prejuízos que poderiam ser causados ao entrevistado com a divulgação de partes das entrevistas. O que teria motivado a supressão de partes do material produzido (Melo, 2015). Outro artigo analisa um tema igualmente importante e raro, o dos efeitos da própria entrevista sobre o entrevistado e o entrevistador:

Será que o eu que pergunta possui estrutura emocional para receber a resposta do outro a que está indagando? E qual é o impacto que se provoca no outro, [...] mas quando se está só, no enfrentamento da alteração sofrida pelo outro no trabalho da memória no presente? (Sousa, 2015, p. 4).

Com frequência menor, mas também em sintonia com um debate que tem crescido no campo em anos recentes, a entrevista foi abordada ainda numa perspectiva narrativa. Em nossa pesquisa introdutória, foi localizado um artigo de 2013 que discute a fabulação na entrevista: recursos ficcionais, grau de confiabilidade e o abandono da busca da verdade: "O que se pode acessar, através da entrevista, não são os fatos, mas as narrativas" (Vaz, 2013, p. 9).

4 "Intercom 40 anos: Comunicação, memórias e historicidades" é o tema do Intercom 2017. 
Apesar das diferenças nos debates propostos, nas abordagens e autores com os quais dialogam, em várias das pesquisas citadas encontramos referências ao livro de Cremilda Medina e, com menor frequência, ao texto de Edgar Morin. Entretanto, como Morin é uma referência importante no livro de Medina, consideramos que os dois trabalhos permanecem significativos. O que pode nos indicar duas coisas: a profundidade desses textos ou a limitação da nossa bibliografia sobre o tema da entrevista. Talvez seja possível ainda somar os dois fatores. Ou seja, a longevidade desses textos pode ser consequência da riqueza dos debates propostos e também da pouca atenção que temos dedicado ao tema. Uma impressão que não é apenas nossa:

É sintomático que, em outros campos, como a História, as Ciências Sociais e a Psicologia, por exemplo, tenha-se tanto material teórico para tratar da entrevista, enquanto que, no Jornalismo, existam tão poucos títulos, ou tão poucas disciplinas a esmiuçar a questão (Musse, 2013, p. 13).

A maior parte dos livros e textos que tratam da entrevista no jornalismo adota uma perspectiva tecnicista. Pensam a entrevista em sintonia com o modo como ela é encarada na prática jornalística convencional: "[...] a formação teórica-prática jornalística instiga mais [...] como se portar para a entrevista, de como questionar o entrevistado, do que para a concretude existencial da relação comunicativa. Mesmo a importância de ouvir o outro é reduzido como procedimento técnico" (Sousa, 2015, p. 2). Como fogem desse padrão, os textos de Medina e Morin se destacaram e permanecem sendo importantes referências de abordagem mais complexa do ato de entrevistar. Tentaremos a seguir discutir alguns dos aspectos importantes que esses textos discutem e, em seguida, elencar também algumas zonas silenciadas.

\section{Morin e Medina}

Quando os trabalhos de Morin e Medina são citados, entre os pontos mais referidos destacam-se as tipologias propostas por ambos. Morin classifica as entrevistas jornalísticas (rádio, televisão e cinema) em função do que define como "Grau de comunicabilidade" da entrevista: Rito, Anedótica, Diálogo e Neoconfissões. Medina as divide em dois grupos, as que reforçariam a espetacularização e as que estimulariam a compreensão ou aprofundamento. No grupo da espetacularização, ela encontra os seguintes perfis de entrevista: Pitoresco, Inusitado, Condenação, Ironia "intelectualizada". No grupo da compreensão: Entrevista conceitual, Entrevista enquete, Entrevista investigativa, Confrontação-polemização, Perfil humanizado. 
Na classificação de Morin, as duas categorias mais profícuas parecem ser a "Entrevista diálogo" e as "Neoconfissões". Segundo ele, quando a entrevista atinge a condição de diálogo, ela vai além de uma conversa. Ocorre uma busca compartilhada, as partes envolvidas atuam colaborativamente para "trazer à tona uma verdade que pode dizer respeito à pessoa do entrevistado ou a um problema" (Morin, 1973, p. 129). É a mesma ideia que sustenta o eixo principal do livro de Medina, desde o título: a entrevista como uma possibilidade de construção de um diálogo profundo:

[...] haverá até a possibilidade de acontecer um ato culminante que se pode nomear como interação social criadora. Neste caso, tanto entrevistado como entrevistador são [...] simplesmente duas pessoas, que se auto-elucidam [...] ao mesmo tempo que se modificam" (Medina, 1995, p. 30-31).

Para caracterizar o diálogo, Cremilda recorre em alguns momentos a Martin Buber. Para ele, o dialógico é uma forma de comportamento dos homens uns com os outros, uma abertura. Assim, pessoas dialogicamente ligadas precisam, necessariamente, estar voltadas umas para as outras. Entre as maneiras de perceber o outro, Buber distingue três. Duas mais distantes - o observador e o contemplador - e uma terceira que ele nomeia como "tomada de conhecimento íntimo", quando o outro "diz algo a mim, transmite algo a mim, fala algo que se introduz dentro da minha própria vida" (Buber, 1982, p. 42). No processo de construção do diálogo, para Medina, atuam a personalidade do entrevistador - mais monológica ou dialógica - e a sua maturidade para lidar com esse encontro, desviando da "agressividade, imposição, autoritarismo" e respeitando as etapas naturais: "namoro, busca da confiança recíproca, entrega". Ela acrescenta ainda que a personalidade do entrevistado, sua disponibilidade, também interfere no resultado.

Um aspecto citado por ambos é a dinâmica de bloqueio e desbloqueio. Morin cita essa tensão quando trata da entrevista nas ciências humanas. A ideia é que, sendo uma intrusão, a entrevista aciona o sistema de defesa do entrevistado, pois soa como agressiva. Ao mesmo tempo, o entrevistado tem grande necessidade de exprimir-se. Citando Carl Rogers, Morin defende que a barreira de defesa pode ser superada apelando-se à necessidade de expressão do entrevistado. Abordando o mesmo fenômeno, Cremilda sugere aos jornalistas: "[...] preparar a atmosfera de trabalho, proporcionar, com habilidades que têm muito de psicológicas, ou pedagógicas, uma abertura para o desbloqueio, o desarmamento" (Medina, 1995, p. 30). 
Outro ponto profícuo do texto de Morin é a ideia de "Neoconfissões". Trata-se de um tipo de entrevista jornalística que funcionaria como uma espécie de divã. Um "striptease da alma" ou confissão que vai além do superficial, da informação, colocando o jornalista no papel de um confessor. O tema da confissão aparece em alguns momentos do texto. Para ele, o pesquisador que trabalha com entrevistas "deveria estar à altura do papel de confessor leigo da vida moderna" (Morin, 1973, p. 123). Em outro momento, aponta razões da demanda por expressão:"[...] uma necessidade intensa e talvez particularmente insaciável em nosso mundo, onde muitos não têm mais o Grande Ouvinte - nem de seu mediador católico, o padre; onde bem poucos - e somente os neuróticos - se beneficiam do neoconfessor, o psicanalista" (Morin, 1973, p. 124). De forma pontual, a formulação inspirou pesquisas. Em seu artigo "Entrevista jornalística, confissão e as neoconfissões na mídia brasileira", Beatriz Marocco, por exemplo, recorre a Morin, Dent e Foucault para abordar "a entrevista, como um modo jornalístico de 'busca da verdade' que se apóia no ritual da confissão" (2008, p. 1).

Na tipologia de Medina é possível destacar também o que ela chama de entrevista de confrontação-polemização. Situação em que a discórdia, ambiguidades e contradições podem ser debatidas sob mediação do jornalista, que exercerá o papel de "porta-voz de dúvidas do senso comum". Se o confronto e até a agressividade fazem parte de um modo de entrevistar celebrado por uns e criticado por outros, o interessante da abordagem de Cremilda é nos lembrar do lado benéfico na polemização. Também é possível encontrar diálogo com essa formulação em pesquisas posteriores. No artigo "A positividade do conflito em entrevistas jornalísticas", Marta Maia e Thales Lelo recorrem a Medina, Buber e Georg Simmel para discutir a ideia de que o conflito propicia uma forma de encontro, derelação,espaçoemqueháreciprocidadeentrecontrários.Umarelação que desencadeia mudanças, por ser "distinta da indiferença". Assim, propõem os autores:"No choque, no embate, jazem sim as sementes do diálogo" (2011, p. 10).

A perspectiva dialogal proposta por Morin e Medina permanece sendo uma referência para quem entende o jornalismo numa perspectiva humanista ou defende que o jornalismo pudesse vir a tornar-se menos hierárquico. Encarar a entrevista jornalística como uma forma de interação complexa e transformadora para ambas as partes não é comum. Assim como aceitar que o sucesso e o fracasso de uma entrevista envolvem a atuação e abertura do entrevistador e do entrevistado. A entrevista jornalística não é entendida usualmente como uma parceria e, sim, como uma situação assimétrica: "O jornalista tem de conduzir a entrevista para onde quer, e não deixar-se conduzir pelo entrevistado para onde este quer" (Sousa, 2001, p. 237-238). A concepção tradicional é a de que há alguém no comando e que este alguém deve ser o jornalista: "Outra chave é 
manter o comando da conversa, impedindo que ela se desvie do tema, seja por digressões do entrevistado, seja pela discussão da validade ou oportunidade da entrevista mesma" (Lage, 2001, p. 80).

\section{Silenciamentos}

Além dos aspectos citados acima, poderíamos destacar vários outros no texto de Morin e no livro de Medina. Entretanto, é oportuno também observar o que não encontramos nesses textos e que talvez também permaneça ausente ou pouco debatido em nossas pesquisas. Como tornar uma entrevista uma "interação social criadora"? Como viver a abertura do diálogo, em que duas pessoas efetivamente se revelam e se auto-elucidam? Percorrendo o livro de Medina, encontramos recomendações poéticas, mas vagas. Ela afirma que alguns "traços revelam o grande toque mágico do entrevistador" (Medina, 1995, p. 30) e enumera: "Uma sensibilidade diferenciada que se manifesta através do gesto, do olhar, da atitude corporal [...] por certo esses fluidos positivos de uma percepção aberta chegarão, por complexos sinais, à percepção do entrevistado" (Medina, 1995, p. 30). Também recomenda: "O toque criador se reforça diante de situações imprevisíveis ou aparentemente intransponíveis. [...] O que é preciso é aceitar os desafios e praticar a criatividade, experimentar as $n$ saídas para atingir o grande fim - o diálogo" (Medina, 1995, p. 31).

As recomendações de Morin sobre a entrevista em ciências humanas são um tanto mais diretas. Mas, ainda assim, talvez também insuficientes. Ele afirma que o modo como as perguntas são elaboradas, a quantidade, assim como a ordem em que elas aparecem na entrevista são fatores que interferem nas respostas. Mas não sugere como lidar com esses aspectos nem dá exemplos. Morin nos alerta para potenciais fatores perturbadores importantes, como as reações possíveis dos entrevistados (inibição, timidez, prudência, mecanismos de atenção e desatenção, exibicionismo etc.), mas não nos indica com negociar com eles. Em determinado momento até dá algumas sugestões, mas de forma bastante sucinta: “O entrevistador deve corresponder a uma imagem simpática e tranquilizadora. Frequentemente a mulher comunicará melhor do que o homem. [...] é preciso também que o pesquisador tenha um interesse profundo pela comunicação, pelo outro" (Morin, 1973, p. 122). A ausência de aprofundamento sobre esses aspectos neste trabalho de Morin é aceitável, pois se trata apenas de um texto curto. O surpreendente é que cada um desses desafios inerentes à entrevista não tenha suscitado diversas outras pesquisas, textos e livros.

Discutiremos aqui alguns desses aspectos silenciados, comparando-os especialmente com perspectivas adotadas na história oral, área que possui 
maior tradição no debate sobre o fazer cotidiano e implicações éticas no trabalho com entrevistas. Um primeiro ponto que poderíamos questionar é a relação de poder entre entrevistadores e entrevistados. Como viver uma interação social criadora, uma abertura efetiva se o poder de decisão permanece exclusivamente com o entrevistador? A regra de impedir o acesso do entrevistado ao material produzido antes da publicação é dominante no jornalismo, aceita inclusive por jornalistas reconhecidamente humanistas, como Eliane Brum: “Não mostro o texto. Acho que é uma relação de confiança" (Mariano, 2011, p. 312). Ou seja, no jornalismo, e também nos textos de Morin e Medina não debatemos 0 "depois" da entrevista. Na relação entre entrevistador e entrevistado há o antes e o durante. A relação esgota-se na medida em que conseguimos acesso ao conhecimento e experiências do entrevistado. $O$ modo como utilizaremos esse conteúdo, fornecido pelo entrevistado e capaz de afetar a sua vida, permanece sendo uma dimensão que não diz respeito a ele. O nosso compromisso é com o leitor, nunca com o entrevistado.

Não há, portanto, qualquer questionamento da autoridade do jornalista, como se fosse possível construir uma interação efetiva mantendo essa distância. Em outras áreas, como na história oral, esse aspecto é encarado de outra forma por muitos. Em vários projetos, a opção é por uma relação transparente com o entrevistado, entendido como colaborador, alguém com quem se trabalha junto. Assim, existem recomendações objetivas de que ele terá acesso ao material editado, poderá indicar alterações e somente então autorizará ou não, por escrito, a divulgação. Essa conferência é encarada como um dever ético (Meihy, 2002).

Não estamos aqui defendendo que procedimento idêntico seja adotado no jornalismo. $O$ interessante é observar que o silêncio a respeito do tema nos impede de encarar a nossa opção evidente pela relação autoritária entre entrevistadores eentrevistados etambém de propornovosarranjos em contextos em que eles seriam possíveis e vantajosos, como em casos de conteúdos biográficos, produções laboratoriais, pingue-pongues com pesquisadores etc. Num mundo em que diversas experiências de criação de conteúdo e espaços de comunicação são guiados por ideias como"generosidade no compartilhamento das informações e saberes, a depuração de erros, a resolução de problemas e a transparência de fontes e processos" (Karam; Christofoletti, 2011, p. 94), a mesquinhez do jornalismo torna-se muito mais evidente.

Ainda sobre a relação entrevistador-entrevistado pode-se discutir os benefícios, simbólicos e financeiros, advindos do compartilhamento do saber alheio. Um tema especialmente pertinente em casos de livros-reportagem e documentários. Em outras áreas tem sido adotado o procedimento de compartilhar os benefícios com aqueles que foram entrevistados e, assim, 
possibilitaram a realização do trabalho. São vários os relatos de que, mesmo com pouca escolarização, muitos começam a perceber que são excluídos dos benefícios gerados pela divulgação de um conteúdo que lhes pertencia, como disse Seu Biu do Maracatu:"[...] eu não quero mais ser entrevistado por ninguém, porque, o que tava dando, e se dá, é o camarada fazer um livro presente com minhas palavras, e se saírem vendendo, ganhando dinheiro, e eu nada tenho" (Montenegro, 2003, p. 24).

Talvez uma perspectiva que naturalize para o jornalista o controle e usufruto exclusivo do material gerado seja a de que o seu papel é o de autor. Para os oralistas, como Meihy (2009), o que se faz com o entrevistado é um trabalho "conjunto. Não é autoria. A história oral nos alivia do papel de autor, de grande explicador. Estou junto produzindo o registro de uma experiência" (informação verbal) ${ }^{5}$. A internet, a ética hacker e as possibilidades da cultura digital também vêm questionando de muitas formas as nossas antigas concepções de autoria que, na verdade, nem são tão antigas assim. A criação colaborativa de softwares livres e o uso de licenças como creative commons são alguns exemplos.

Como conduzir a entrevista? Como elaborar as perguntas? Quando não perguntar? Apesar de ser um tema tão relevante para o jornalismo, o nosso debate é limitado e vago. Morin e Medina dão sugestões que têm mais a ver com um estado de espírito do que com a experiência efetiva da entrevista. A incipiência da nossa abordagem sobre esse aspecto fica mais evidente quando localizamos, em outras áreas, referências explícitas, por exemplo, a certas formulações de perguntas e efeitos que podem desencadear:

Diferentes tipos de perguntas provocam diferentes tipos de resposta. Se o objetivo da entrevista for registrar histórias, é importante que as perguntas sejam feitas nesse sentido [...]

Perguntas descritivas: Uma pergunta do tipo "Como era a casa da sua infância?" [...]

Perguntas que evocam movimento: "O que você fez depois que você saiu de sua casa?" [...] Assim como algumas perguntas contribuem para a construção da narrativa, outras têm o efeito inverso. Assim, vale evitar:

Perguntas genéricas: Uma pergunta do tipo "Como foi sua infância? Estimula que o entrevistado dê uma resposta genérica, como "boa, "ruim" $[. .$.

Perguntas com pressupostos: [...] Quais situações de exclusão que o senhor vivenciou como idoso? (Memória, 2006, p. 220).

5 Informação fornecida em aulas de José Carlos Meihy na Pós-Graduação em História Social da FFLCHUSP. 
Quando o interesse recai sobre a vida de um personagem, a opção por escutar mais e perguntar menos é consciente, para que o entrevistado construa a sua narrativa: "Quanto menos o entrevistador falar, melhor. A participação do entrevistador deve ser sempre estimuladora e jamais de confronto" (Meihy, 2002 , p. 132). Exatamente porque, sabendo que se trata do terreno da memória, abandona-se a preocupação com a precisão dos fatos.

Novamente não se trata aqui de propor a adoção de procedimentos de outras áreas, mas de destacar que o nosso silêncio sobre esses aspectos nos impede de problematizá-los e ter consciência dos efeitos das nossas escolhas. E, assim, ajustar melhor o "como perguntar", "quando perguntar", "quando calarse". E também outras dimensões, anteriores e posteriores ao momento da entrevista. Que jornalista estaria mais apto a abordar determinado assunto com determinada fonte por conta do seu óbvio implicamento com tais questões (gênero, etnia, faixa etária etc.)? Que consequências a divulgação do que foi dito pode ter sobre a vida do entrevistado? Num exemplo raro de sensibilidade ao tema, a jornalista Elaine Brum afirma:

\begin{abstract}
Acho que tem uma coisa importante para quem é jornalista: as pessoas sabem que a história delas vai ser publicada, que aquilo que estão dizendo vai ser publicado. Elas sabem, mas elas não sabem. E essa é a nossa responsabilidade. Uma responsabilidade enorme, porque nenhuma matéria é mais importante do que uma pessoa. E tu tem a obrigação de, por mais extraordinária que seja aquela história, aquela informação, de dizer para a pessoa o que realmente pode e provavelmente vai acontecer quando ela contar a sua história e ela for publicada no dia seguinte e milhões de pessoas lerem (Mariano, 2011, p. 314).
\end{abstract}

Como último ponto, destaco a limitação da nossa abordagem sobre entrevistas com temas traumáticos. Morin indica uma dimensão importante de qualquer entrevista: a terapêutica. E comenta a possibilidade de contribuição para que o indivíduo se auto-elucide, tome consciência de si. Citando a conversação freudiana, explica que são provocados processos psico-afetivos, levando à catarse. Se, em outros contextos, esse "efeito liberatório, purificador, e, ou mesmo, em psicopatologia, um efeito de cura" (Morin, 1973, p. 116) é encarado com clareza, o mesmo não ocorre no jornalismo. O lembrete de Morin é que a entrevista jornalística também envolve considerável energia afetiva:"No domínio do rádio e da televisão, a entrevista pode ter um efeito psico-afetivo profundo, que ultrapassa, de muito, a estrita missão de informar" (Morin, 1973, p. 116). E tratando-se de entrevistas que são feitas, necessariamente, para serem 
publicizadas, a entrevista jornalística lida com uma liberação de energia afetiva que é transmitida ao público e o afeta.

Portanto, entrevistado, público e também - acrescentamos nós o entrevistador podem ser afetados pela entrevista. Mas como lidar com emoções desencadeadas no curso de uma entrevista? Quem buscar respostas nas pesquisas de jornalismo dificilmente as encontrará. No campo da medicina narrativa e história oral, alguns já pensaram sobre o tema. Descrevendo um projeto que envolvia entrevistas em vídeo com sobreviventes do Holocausto ${ }^{6}$, Mary Clark explica:

Parte do refinamento do processo de trabalhar com testemunhos, sobre o qual Laub começou a discorrer, foi a conclusão de que era importante ter dois entrevistadores presentes à hora da entrevista. Ele foi bastante claro com relação ao objetivo disso: além de prestar apoio ao entrevistador principal, o segundo evita que o primeiro seja atraído para as profundezas do trauma junto com o narrador (Clark, 2009, p. 168).

\section{Considerações finais}

O intuito aqui foi identificar características do debate sobre o tema da entrevista nos estudos da comunicação, destacando alguns pontos altos e silenciamentos. Partindo de artigos do maior congresso da área, descrevemos alguns eixos mais comuns na abordagem da entrevista: discurso, interação, memória, narrativa. Entre os aportes mais recorrentes nessas pesquisas, localizamos dois trabalhos, de Edgar Morin e Cremilda Medina. São diversas as contribuições de ambos no sentido de complexificar o tratamento do tema e por isso permanecem sendo referências. Entretanto, se Morin e Medina nos deram contribuições valiosas, parece que avançamos pouco além deles.

Além da descrição dealgumaszonas cinzentas do debate sobrea entrevista jornalística, buscamos mostrar que os mesmos pontos são abordados de frente em outras áreas. Possivelmente, o interesse crescente pelo tema da memória na comunicação poderá nos auxiliar nisso. Se, como afirmam alguns pesquisadores, a Sociologia foi a principal base que alimentou as reflexões sobre o jornalismo e as Teorias do Jornalismo, existem lacunas nessas reflexões que poderiam ser abordadas com apoio da Teoria da História (Matheus, 2011). E, acrescentamos nós, em diálogo com a História Oral e outras áreas que tenham relação intensa

6 Professores da Yale University, Dori Laub, da psiquiatria e Geoffey Hartman, da literatura, são os fundadores da Fortunoff Archive for Holocaust Testimonies. 
com a entrevista e em diálogo com novas condutas, éticas e demandas que vêm surgindo em consequência da digitalização da comunicação.

No jornalismo, a experiência com a entrevista é abundante. Uma prática tão frequente poderia se traduzir em expertise, desde que houvesse também reflexão sobre essa prática, aprendizado com os erros e acertos, transformação constante. Mas o jornalismo tende ao espontaneísmo, exercendo pouca autocrítica. Esse quadro talvez exerça influência também sobre os pesquisadores, muitos com formação e experiência profissional em jornalismo, o que explicaria a limitação do nosso debate sobre um aspecto tão central. Cláudia Lago nos alerta para o risco, como pesquisadores com formação em jornalismo, de estarmos sujeitos "a uma percepção bastante marcada pelo próprio campo. É o caso, portanto, de perguntarmos se o fato de pertencermos aos grupos que pesquisamos não deve ser pesado em termos metodológicos" (Lago, 2010, p. 57). E, reconhecendo o problema, buscar modos de superá-lo. Para que, assim, a experiência jornalística com a entrevista possa trazer contribuições mais densas para quem pratica e estuda a entrevista, no jornalismo e em outros campos. $\mathrm{E}$ para que o jornalismo finalmente possa - diminuindo a sua arrogância e saindo da zona de conforto - rever, criticar e modificar suas condutas.

\section{REFERÊNCIAS}

BRAGA, José L. Roda Viva - uma encenação da esfera pública. In: CONGRESSO BRASILEIRO DE CIÊNCIAS DA COMUNICAÇÃO, 29., 2006, Brasília. Anais... Brasília: UNB, 2006.

BUBER, Martin. Diálogo. In: Do diálogo e do dialógico. São Paulo: Perspectiva, 1982, p. 33-75.

CLARK, Mary M. Vídeo-testemunhos sobre o Holocausto, Hstória Oral e Medicina Narrativa: a luta contra a indiferença. Oralidades, São Paulo, ano 3, n. 5, p. 159175, jan./jun., 2009.

D'ALMEIDA, Alfredo D. O processo de construção de personagens em documentários de entrevista. In: CONGRESSO BRASILEIRO DE CIÊNCIAS DA COMUNICAÇÃO, 29., 2006, Brasília. Anais... Brasília: UNB, 2006.

DIAS, Verônica F. Da pessoa ao personagem - a construção de "Vera" no documentário "Santo forte", de Eduardo Coutinho. In: CONGRESSO BRASILEIRO DE CIÊNCIAS DA COMUNICAÇÃO, 30., 2007, Santos. Anais... Santos: Unisanta, 2007.

GIACOMINI, Jair. A entrevista em cena. In: CONGRESSO BRASILEIRO DE CIÊNCIAS DA COMUNICAÇÃO, 35., 2012, Fortaleza. Anais... Fortaleza: Unifor, 2012. 
GONÇALVES, Denise R. Convergências: mídias, gêneros e pesquisa empírica em Comunicação. CONGRESSO BRASILEIRO DE CIÊNCIAS DA COMUNICAÇÃO, 35., 2012, Fortaleza. Anais... Fortaleza: Unifor, 2012.

INTERCOM, São Paulo. Disponível em: http://www.portalintercom.org.br/eventos1/ congresso-nacional/apresentacao5. Acesso em: 10 mai. 2017.

KARAM, Francisco José Castilhos; CHRISTOFOLETTI, Rogério. Fundamentos jornalísticos para novos cenários éticos da informação. In: SILVA, G.; KÜNSCH, D.; BERGER, C.; ALBUQUERQUE, A. (Org.). Jornalismo contemporâneo: figurações, impasses e perspectivas. Salvador: EDUFBA; Brasília: Compós, 2011. p. 79-100. Disponível em:https://repositorio.ufba.br/ri/bitstream/ri/1586/1/Jornalismo\%20 contemporaneo.pdf. Acesso em: 21 abr. 2017.

KLOCKNER, Luciano. A entrevista radiofônica: uma análise através da Teoria da Relevância. In: CONGRESSO BRASILEIRO DE CIÊNCIAS DA COMUNICAÇÃO, 29., 2006, Brasília. Anais... Brasília: UNB, 2006.

LAGE, Nilson. A reportagem: teoria e técnica de entrevista e pesquisa jornalística. Rio de Janeiro: Record, 2001.

LAGO, Cláudia. Antropologia e Jornalismo: uma questão de método. In: LAGO, C.; BENETTI, M. (Org.). Metodologia de pesquisa em jornalismo. Petrópolis: Vozes, 2010. p. 48-66.

LAMAS, Caio e outros. A produção audiovisual na pesquisa empírica: a experiência do núcleo de pesquisa em comunicação e censura da ECA-USP. In: CONGRESSO BRASILEIRO DE CIÊNCIAS DA COMUNICAÇÃO, 34., 2011, Recife. Anais... Recife: Unicap, 2011.

MAIA, Marta R.; LELO, Thales V. A positividade do conflito em entrevistas jornalísticas. In: SBPJor - ENCONTRO NACIONAL DE PESQUISADORES EM JORNALISMO, 9., 2011, Rio de Janeiro. Anais... Rio de Janeiro: UFRJ, 2011.

MARIANO, Agnes. Eliane Brum e a arte da escuta. Em Questão, Porto Alegre, v. 17, n. 1, p. 307-322, jan./jun. 2011.

MAROCCO, Beatriz. Entrevista jornalística, confissão e as neoconfissões na mídia brasileira. In: SBPJor - ENCONTRO NACIONAL DE PESQUISADORES EM JORNALISMO, 6., 2008, São Paulo. Anais... São Paulo: UMESP, 2008..

MARTINEZ, Monica. O Jornalista que Escutava: Joseph Mitchell e o Jornalismo Literário. In: CONGRESSO BRASILEIRO DE CIÊNCIAS DA COMUNICAÇÃO, 30., 2007, Santos. Anais... Santos: Unisanta, 2007.

MATHEUS, Leticia C. Comunicação, tempo, história: tecendo o cotidiano em fios jornalísticos. Rio de Janeiro: Mauad X: Faperj, 2011. 
MEDINA, Cremilda. Entrevista: o diálogo possível. São Paulo: Ática, 1995.

MEIHY, José Carlos S. B. Manual de história oral. São Paulo: Loyola, 2002.

MELO, Cristina T. V. de. Ética, Estética e Política no Vídeo Vida Estelita. In: CONGRESSO BRASILEIRO DE CIÊNCIAS DA COMUNICAÇÃO, 38., 2015, Rio de Janeiro. Anais... Rio de Janeiro: UFRJ, 2015.

MEMÓRIA falada: memória, rede e mudança social. São Paulo: SESC SP: Museu da Pessoa: Imprensa Oficial do Estado de SP, 2010.

MONTENEGRO, Antonio T. História oral e memória: a cultura popular revisitada. São Paulo: Contexto, 2003.

MORIN, Edgar. A entrevista nas ciências sociais no rádio e televisão. In: MOLES, Abraham e outros. Linguagem da cultura de massas: televisão e canção. Petrópolis: Editora Vozes, 1973. p. 115-135.

MUSSE; Christina F.; ARANTES, Haydêe S. Telejornalismo e memória: narrando a cidade pelas histórias de vida. In: CONGRESSO BRASILEIRO DE CIÊNCIAS DA COMUNICAÇÃO, 35., 2012, Fortaleza. Anais... Fortaleza: Unifor, 2012.

MUSSE, Christina F. Histórias de vida no Telejornalismo: Geneton Moraes Neto revisita Joel Silveira. In: CONGRESSO BRASILEIRO DE CIÊNCIAS DA COMUNICAÇÃO, 36., 2013, Manaus. Anais... Manaus: UFAM, 2013.

PESSOA, Sônia C. Itatiaia Patrulha: as histórias da vida. In: CONGRESSO BRASILEIRO DE CIÊNCIAS DA COMUNICAÇÃO, 28., 2005, Rio de Janeiro. Anais... Rio de Janeiro: UERJ, 2005.

PRATA, Nair. Aspectos do Discurso Radiofônico - A Entrevista. In: CONGRESSO BRASILEIRO DE CIÊNCIAS DA COMUNICAÇÃO, 28., 2005, Rio de Janeiro. Anais... Rio de Janeiro: UERJ, 2005.

PUHL, Paula R.; PERSCH, Dionéia. O papel do repórter nos programas que unem entretenimento e informação: estudo do quadro Proteste Já do CQC. In: CONGRESSO BRASILEIRO DE CIÊNCIAS DA COMUNICAÇÃO, 35., 2012, Fortaleza. Anais... Fortaleza: Unifor, 2012.

RUELA, Raul M. Sócrates vai ao programa de entrevista na TV: análise de técnicas de diálogo no "Roda Viva". In: CONGRESSO BRASILEIRO DE CIÊNCIAS DA COMUNICAÇÃO, 34., 2011, Recife. Anais... Recife: Unicap, 2011.

SODRÉ, Muniz; PAIVA, Raquel. Informação e boato na rede. In: SILVA, G.; KÜNSCH, D.; BERGER, C.; ALBUQUERQUE, A. (Org.). Jornalismo contemporâneo: figurações, impasses e perspectivas. Salvador: EDUFBA; Brasília: Compós, 2011. p. 21-32. Disponível em: https://repositorio.ufba.br/ri/bitstream/ri/1586/1/ Jornalismo\%20contemporaneo.pdf. Acesso em: 21 abr. 2017. 
SOUSA, Gerson de. A produção de sentido no processo comunicativo: a construção da entrevista como conflito na memória e identidade do sujeito jornalista. In: CONGRESSO BRASILEIRO DE CIÊNCIAS DA COMUNICAÇÃO, 38., 2015, Rio de Janeiro. Anais... Rio de Janeiro: UFRJ, 2015.

SOUSA, Jorge P. Elementos de jornalismo impresso. Covilhã: Biblioteca Online de Ciências da Comunicação (BOCC), 2001. Disponível em: http://www.bocc.ubi.pt/ pag/sousa-jorge-pedro-elementos-de-jornalismo-impresso.pdf. Acesso em: 22 nov. 2012.

VAZ, Ana L. Objetividade e Ruído na Produção Jornalística. In: CONGRESSO BRASILEIRO DE CIÊNCIAS DA COMUNICAÇÃO, 36., 2013, Manaus. Anais... Manaus: UFAM, 2013.

Recebido em: 4/8/2017

Aceito em: 30/10/2017

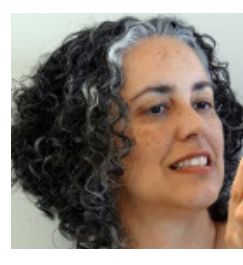

Dados da autora:

Agnes Francine de Carvalho Mariano | agnesmariano@gmail.com

Professora da pós-graduação em Comunicação e Temporalidades e da graduação em Jornalismo da

Universidade Federal de Ouro Preto. Doutora em Ciências da Comunicação pela Escola de Comunicações e

Artes (ECA) da Universidade de São Paulo (2013).

Endereço da autora

Universidade Federal de Ouro Preto (UFOP)

Rua do Seminário, $\mathrm{s} / \mathrm{n}^{\circ}$ - Centro

35420-000 - Mariana (MG) - Brasil 